\title{
Rescate y adopción de embriones criopreservados: ¿solidaridad o encarnizamiento reproductivo?
}

\author{
María Alejandra Carrasco \\ FACULTAD DE FILOSOFÍA \\ PONTIFICIA UNIVERSIDAD CATÓLICA DE CHILE \\ mcarrasr@uc.cl
}

Resumen: En este artículo postulo que, analizado a la luz de las enseñanzas del Magisterio de la Iglesia, tanto el llamado rescate como la adopción de embriones criopreservados abandonados debe considerarse una acción moralmente ilícita, al margen de la buena intención de las rescatistas y las trágicas circunstancias de los embriones. A diferencia de otros autores que se oponen por razones prudenciales o la relación de esta adopción con los bienes del matrimonio, yo propongo que el objeto de esta acción, la transferencia heteróloga de un embrión criopreservado, es en sí una violación a la dignidad del embrión y en cuanto tal un mal intrínseco. Este es uno de los difíciles casos en que el respeto a la dignidad de la persona obliga a respetar su muerte antes que empeñarse por cualquier medio por salvar su vida.

Palabras clave: Adopción prenatal, rescate de embriones, embriones criopreservados, dejar morir, dignidad de la persona.

Abstract: In this paper I propose that, when analyzed according to the teachings of the Church, both prenatal adoption and the so-called rescue of frozen embryos should be considered as morally impermissible. The good intentions of the rescuers and the tragic circumstances of the embryos don't change the intrinsic evil of the object of this action, i.e. a heterologous transfer. Unlike other commentators, my argument is not related to prudential reasons or the sanctity of marital intercourse, but exclusively to the violation of the embryo's dignity. This is one of the difficult cases in which respect for human dignity requires to respect its death rather than commit oneself to any means to save its life.

Keyword: Prenatal adoption, rescue, frozen embryos, letting die, human dignity. 
Los rápidos avances de la ciencia y de la biotecnología apremian a la Teología y a la Filosofía para establecer la licitud moral de sus intervenciones. Las crecientes posibilidades técnicas para intervenir la vida humana obligan a profundizar en la reflexión acerca de la naturaleza del ser humano y el significado de las acciones del hombre. Solo mediante una profunda comprensión antropológica es posible determinar cuándo las diversas técnicas biomédicas son moralmente permisibles y cuál es el fundamento último de ese juicio.

Así fue como, por ejemplo, el descubrimiento de la píldora anticonceptiva y luego la posibilidad de la Fecundación in Vitro (FIV) llevaron a una intensa reflexión acerca del significado de la sexualidad y del amor humano, hasta llegar a ver que la donación mutua de un hombre y una mujer solo se completa y hace plenamente humana cuando no separa sus dos fines esenciales, el unitivo y el procreativo. Esos descubrimientos científicos y tecnológicos fueron los que, en última instancia, indujeron a un discernimiento más acabado del valor antropológico de la sexualidad y del amor esponsal, a poner ante los ojos su dinámica interna y mostrarse como el único lugar verdaderamente digno para el origen de una nueva persona ${ }^{1}$. La comprensión más lúcida de la especificidad de esta acción humana llevó a que el Magisterio condenara tanto la píldora anticonceptiva como la FIV. En otros casos, como la posibilidad técnica para realizar trasplantes de órganos, también produjeron debates que fueron aclarando los bienes en juego. A diferencia de la píldora y la FIV, en esta materia se concluyó que esta intervención era moralmente lícita e incluso a veces supererogatoria ${ }^{2}$.

En este último tiempo se ha generado una fuerte controversia en torno a una nueva posibilidad que las técnicas biomédicas ofrecen: El llamado rescate y la adopción de embriones criopreservados que han sido

1 En este artículo usaré indistintamente los términos ser humano y persona, sin entrar en el debate contemporáneo al respecto y asumiendo que todo ser humano es persona desde el momento de la concepción.

2 La discusión se refería a si los trasplantes constituían una mutilación o no. Tras debatirlo se concluyó que en este caso había que aplicar el principio de solidaridad, en el que aun admitiendo una mutilación objetiva se debe ponderar la acción en su totalidad y considerar que se hace en beneficio de otro. Este caso es interesante pues hay autores que afirman el paralelismo este análisis y el apropiado para el rescate y/o adopción prenatal. 
abandonados por sus padres genéticos ${ }^{3}$. Se discute si esta(s) práctica(s) son acciones lícitas o si por el contrario constituyen un mal moral. Las opiniones son tan diversas que van desde quienes las consideran acciones supererogatorias que como los trasplantes son un testimonio de solidaridad; hasta quienes piensan que son prácticas intrínsecamente malas y deben ser prohibidas por la Iglesia, pues representan un nuevo intento del hombre por hacerse dueño y controlador de la vida, un "encarnizamiento reproductivo" 4 .

En este artículo discutiré la moralidad de estas prácticas a la luz de las enseñanzas del Magisterio de la Iglesia 5 . Comenzaré con el llamado rescate, aunque luego también mostraré por qué el análisis puede hacerse extensivo a la adopción prenatal ${ }^{6}$. Por rescate entenderé 'la acción

3 Se entiende por adopción la de una mujer (o pareja) que decide embarazarse con un embrión criopreservado abandonado y brindarle una familia; y por rescate el de una mujer que decide embarazarse con un embrión criopreservado abandonado para luego darlo en adopción.

4 El término lo utiliza L. M. PASTOR ("Análisis y comentario ético del documento Dignitas Personae: Desde la continuidad a la novedad" en Cuadernos de Bioética XXII [2011/1] 29) sugiriendo una analogía con el llamado encarnizamiento terapéutico o las intervenciones médicas desproporcionadas que se empeñan en evitar la muerte de enfermos terminales aun a costa de la violación de su dignidad.

5 Me apoyaré fundamentalmente en las encíclicas Veritatis Splendor (1993. En adelante VS), Evangelium Vitae (1995. En adelante EV), y las Instrucciones Pastorales Donum Vitae (1987. En adelante DV) y Dignitas Personae (2007. En adelante DP).

6 Inicialmente centraré el análisis en el rescate para no confundir mi argumentación con las interpretaciones que se dan de DP 19 donde, aunque se condena explícitamente la adopción prenatal y algunos autores lo entienden como una condena general (cf. PASTOR, p. 39), muchos piensan que el texto es ambiguo. La Instrucción afirma que: "Para dar la oportunidad de nacer a tantos seres humanos [criopreservados] se ha planteado la idea de una 'adopción prenatal'. Se trata de una propuesta basada en la loable intención de respetar y defender la vida humana que, sin embargo, presenta problemas éticos no distintos a los ya mencionados" (DP 19). Los "ya mencionados", según dice el párrafo anterior, son "las mismas razones que hacen ilícita tanto la procreación artificial heteróloga como toda forma de maternidad subrogada; esta práctica [poner a los embriones criopreservados abandonados a disposición de parejas estériles] implicaría además otros problemas de tipo médico, psicológicos y jurídicos”. Más adelante explicaré estas razones. Por ahora baste recordar que tanto la fecundación artificial heteróloga como la maternidad subrogada son declaradas como acciones intrínsecamente malas (DV II.A.2 y DV.II.A.3 respectivamente) pues “[o]fende[n] la dignidad y el derecho del hijo a ser concebido, gestado, traído al mundo y educado por los propios padres; 
de transferiry gestar un embrión criopreservado abandonado en el útero de una mujer que no es su madre genética para salvarle la vida' ${ }^{7}$. Mi tesis será que, a pesar de su apariencia de bondad, el rescate no es ni nunca podrá ser una alternativa éticamente aceptable puesto que constituye una acción intrínsecamente mala. En general, los autores que se oponen al rescate (y/o adopción) aducen razones prudenciales (que no convierten a la acción mala en sí misma) o señalan que este violaría los bienes propios del matrimonio. Sin embargo, mi argumento será que, al margen de cualquier otro aspecto que se pueda agregar, la acción del rescate es intrínsecamente mala en primerísimo lugar por cuanto ofende la dignidad del embrión. Todos los otros aspectos agravan o atenúan esta calificación, pero no la cambian.

En la Primera Parte del artículo daré las razones de la maldad intrínseca de la acción del rescate y concluiré explicando por qué, por extensión, estas también se aplican a la adopción prenatal. En la Segunda Parte refutaré algunos de los argumentos más habituales que apoyan el rescate y/o la adopción prenatal, considerándolo un acto heroico e incluso una "obligación de misericordia cristiana".

\section{PRIMERA PARTE}

Criterios de valoración moral

\section{Un problema no zanjado: Embriones abandonados}

Actualmente hay millones de embriones criopreservados en el mundo (solo en Estados Unidos se calculan más de 600.000), muchos de ellos abandonados por sus padres. Por lo general, pertenecen a una pareja que se sometió a una FIV y decidió mantener congelados a los embriones

instaura, en detrimento de la familia, una división entre los elementos físicos, psíquicos y morales que la constituyen” (DV II A 3). De lo anterior se sigue que el Magisterio declararía ilícita la adopción prenatal (o al menos alguna de sus formas) "por las mismas razones" que afirma la maldad intrínseca de la fecundación artificial heteróloga y maternidad subrogada.

7 La adopción prenatal es la acción de transferir y gestar un embrión criopreservado abandonado en el útero de una mujer que no es su madre genética para salvar su vida y/o para formar una familia.

8 G. GRISEZ, "Should a woman try to bear her dead sister's frozen embryo?" en The way of Lord Jesus, vol. 3 (Franciscan Press, Illinois, 1997) 239-244. 
que no fueron implantados pensando en un eventual embarazo futuro, que nunca llegó a realizarse. Estos embriones quedaron sumergidos en nitrógeno líquido, en un estado de "animación suspendida" que les impide tanto morir como crecer y desarrollarse de modo natural. Si no son implantados en el útero de una mujer, su destino es el desecho o bien su uso para la investigación. Ambas opciones implican su muerte. Esta tragedia es la que ha llevado a proponer como la única solución posible que alguna mujer, distinta a la madre, acepte gestarlos y darles la oportunidad de nacer.

Dentro de la Iglesia y entre pensadores cristianos se discute la licitud moral de este tipo de embarazo heterólogo. Hay quienes consideran que sería un gesto heroico de la mujer, un acto supererogatorio que daría un testimonio claro del valor y respeto a la vida. Otros piensan que tal acción sería moralmente ilícita ${ }^{10}$. En el segundo grupo hay quienes señalan que sería una acción intrínsecamente mala y otros la rechazan por razones prudenciales, como el riesgo de un tráfico de embriones o una eventual cooperación material al mal. En el caso del rescate también se rechaza por el abandono en que volvería a quedar el niño tras su nacimiento, y en el de la adopción, porque al no poder proporcionar una familia adecuada se podría terminar aceptando el embarazo de mujeres solteras, parejas de mujeres lesbianas, etc. ${ }^{11}$.

En 1997 la Instrucción Donum Vitae señaló que los embriones sobrantes de la FIV "quedan expuestos a una suerte absurda, sin que sea posible ofrecerles vías de supervivencia seguras y lícitamente perseguibles" (DV I 5) ${ }^{12}$; y posteriormente la Dignitas Personae repite que estos embriones, y en particular los criopreservados, son puestos en "una situación de injusticia que es de hecho irreparable" (DP 19). Pero quie-

9 El término lo utiliza E. BONET FARriol en "El debate teológico sobre el destino de los embriones humanos criopreservados" (http://dspace.unav.es/dspace/ bitsteam/10171/6702/1/ENRIQUE\%20BONET\%20FARRIOL.pdf).

10 Para un catálogo de autores y sus posiciones, cf. Bonet, "El debate...", 497-500. Por ejemplo, entre los defensores de esta práctica se encuentran G. Grisez, C. Brugger y G Miranda; y entre sus oponentes, C. Young, N. Tonti-Filippini y M. Geach.

11 Estas razones las analizaré en la Segunda Parte de este artículo.

12 Nótese que el autor no considera la transferencia al útero de otra mujer. Posteriormente, la DP 19 cita a Juan Pablo II diciendo que no existe salida moralmente lícita para los embriones criopreservados y tampoco plantea la transferencia del embrión a otra mujer, aunque en ella sí se alude al tema de la adopción prenatal. 
nes defienden la licitud e incluso heroísmo de la disponibilidad de una mujer para rescatar al embrión abandonado y permitirle vivir, arguyen que esta opción abriría una luz de esperanza ante la sentencia de muerte que pesa sobre estos seres humanos inocentes.

El argumento decisivo para quienes defienden esta postura es el respeto a la vida desde su concepción hasta su muerte natural ${ }^{13}$. Sin duda este es un argumento muy potente que, en principio, sobrepasa todas las razones prudenciales para oponerse al rescate. Por ello lo que corresponde analizar primero no son las consecuencias ni los posibles riesgos a los que puede llevar el rescate de embriones, sino el objeto mismo de la acción: Discernir, a fin de cuentas, si embarazarse de un embrión abandonado es o no una acción intrínsecamente mala, "a la luz de una concepción antropológicamente correcta de la sexualidad y del matrimonio" (DV Conclusión); fiel a la que propone el Magisterio en sus diversos documentos.

\section{La calificación moral}

La ciencia y la tecnología, en sí mismas, no poseen calificación moral. De acuerdo con el Magisterio, el valor ético de las intervenciones biomédicas debe ponderarse en referencia tanto (1) al respeto incondicional debido a cada ser humano en todos los momentos de su existencia como (2) a la tutela de la especificidad de sus actos personales, como por ejemplo aquellos que transmiten la vida (cf. DP 10). Una intervención médica es lícita cuando busca ayudar a que las personas realicen esos actos que les son propios. Pero al contrario, se pervierte y atenta contra la dignidad humana cuando altera la naturaleza de esos actos, cuando su fin no es ayudar sino obstruir el cumplimiento de su fin natural, o bien sustituir esos actos por técnicas artificiales que le quitan su sentido humano (cf. DP 12) ${ }^{14}$.

13 E. Furton, "On the disposition of frozen embryos" en Ethics and Medics 26 (2001) 2. El autor señala que "entregarlos para la adopción es muy preferible a dejarlos morir".

14 A pesar de que DP 12 se refiere a las técnicas de fertilización artificial, la razón que da para sostener este criterio ("su relación con la dignidad de la persona") permite extenderlo a cualquier intervención que no respete la especificidad y significado de las acciones humanas y viole con ello la dignidad de la persona. Ver también DP 4. 
Este es el criterio con el que Magisterio valora éticamente los diversos procedimientos biomédicos que van surgiendo, alabándolos cuando están al servicio de la vida y el bien humano integral, y condenándolos cuando se oponen e impiden que la persona alcance su plenitud y el fin que le es propio.

\section{Peligros culturales}

Con todo, y a pesar de la claridad del criterio señalado, la reflexión filosófica que busca ser consistente con las enseñanzas de la Iglesia está expuesta a un permanente peligro. El contexto cultural y el paradigma de conocimiento eficientista de nuestra sociedad nos induce muchas veces y de modo inconsciente a juzgar con los criterios propios de la mentalidad técnica de nuestra época, ponderando entre sí los valores que se persiguen para obtener un bien mayor (proporcionalismo ético), o juzgando como moralmente lícitas aquellas conductas que produzcan un mejor estado de mundo o la maximización de los efectos buenos para el mayor número de personas (consecuencialismo moral) (cf. VS 74,75). Las éticas que respaldan estos tipos de deliberación adquieren fuerza persuasiva por su afinidad con el pensamiento cientificista imperante, pero no son fieles a la doctrina de la Iglesia, en cuanto creen poder justificar comportamientos "contrarios a los mandamientos de la ley divina y natural" (VS 76); esto es, contrarios a la naturaleza humana.

El peligro es aun mayor en la reflexión acerca de los orígenes de la vida, en particular al pensar en los embriones humanos. Muchas veces, siguiendo el paradigma de conocimiento imperante, tendemos sin percatarnos a considerarlos como objetos entre objetos y no como sujetos con dignidad. El problema puede deberse a algo tan simple como a que no vemos, ni en su figura ni en sus capacidades actuales, ninguna semejanza con las personas que conocemos; y requerimos de un razonamiento para darnos cuenta de que poseen igual dignidad y merecen el mismo respeto que un adulto plenamente desarrollado ${ }^{15}$. A pesar de nuestro convencimiento de su igual dignidad, si no estamos alerta, intuitivamente tendemos a razonar respecto de ellos de un modo distinto a como lo haríamos, por ejemplo, respecto de un niño. Así, si bien nos opone-

15 El caso es análogo al del aborto. Sin ver cómo se mata a una persona, resulta psicológicamente más fácil aceptar ese matar deliberado de un inocente que cualquier otro asesinato que se realice frente a nuestros ojos. 
mos con la mayor convicción al desecho de embriones, no sentimos la misma violencia que si viéramos una eliminación masiva de niños pequeños, ni sentimos la misma repulsión hacia los médicos y tecnólogos que realizan esos procesos que la que tendríamos hacia el genocida que mata niños frente a nuestros ojos.

Respeto a la vida, respeto a la dignidad

La vida es siempre un bien y es deber de todos protegerla, más aun cuando se trata de la vida de un ser humano inocente. Pero, ¿qué hace que la vida sea un bien? La Evangelium Vitae profundiza en esta verdad afirmando que la vida es siempre un bien porque "al hombre se le ha dado una altísima dignidad que tiene sus raíces en el vínculo íntimo que lo une a su Creador: En el hombre se refleja la realidad misma de Dios" (EV 34. Cursivas mías). Esta dignidad, por su parte, implica la indisponibilidad de las personas, quienes a diferencia de animales y cosas no pueden ser sometidas al dominio de nadie (cf. EV 19) ${ }^{16}$. En otras palabras, que una persona sea indisponible (o sujeto de dignidad) significa que no puede ser cosificada, manipulada, tratada como un inferior. Nadie tiene derecho a tratar a otra persona como si fuera un objeto, a disponer de ella a voluntad.

De aquí se sigue que el valor de la vida se fundamenta en la dignidad de la persona humana. "La inviolabilidad del derecho a la vida del ser humano inocente es un signo y una exigencia de la inviolabilidad de la persona" (DV Introd. 4. Cursivas mías). La vida se respeta porque se respeta la dignidad de la persona. $\mathrm{Si}$ "nadie, en ninguna circunstancia, puede atribuirse el derecho a matar de modo directo a un ser humano inocente" (EV 53), es porque ello sería disponer del otro, tratarlo como un inferior, ofender su dignidad. Por esto es que "el respeto a la vida exige que la ciencia y la técnica [y toda acción de una persona respecto de otra] estén siempre ordenadas al hombre y a su desarrollo integral [...] a promover la dignidad de cada persona humana, en todo momento y condición de vida" (EV 81. Cursivas mías).

Para el análisis del rescate de embriones es fundamental tener presente que el respeto a la vida se funda en el respeto a la dignidad de la persona;

16 La indisponibilidad es una verdad accesible a la razón natural, un dato de la experiencia reconocido universalmente. De hecho, toda la doctrina de los derechos humanos se sustenta en ella (cf. EV 34 y EV 19). 
que el respeto a la vida no es absoluto ${ }^{17}$ mientras que "las exigencias absolutamente irrenunciables son las de la dignidad del hombre" (VS 96). Ahora bien, como el respeto a la vida es una manifestación del respeto a la dignidad de la persona, no es siempre fácil discernirlos. Pero hay algunos casos en que parecerían colisionar (aunque como veremos no es una colisión sino otro modo de manifestar el respeto), y entonces sí se ve con claridad cuál es el fundamento y cuál su consecuencia. Por consiguiente, si en alguna situación hubiera que optar entre "salvar una vida" o "respetar la dignidad de la persona", habría que elegir el respeto a la dignidad. Vale decir, siempre se debe resguardar el bien de la vida salvo que sea a costa de violar la dignidad de esa persona.

\section{Qué es el respeto a la dignidad}

La acción que respeta la dignidad es aquella que se ordena al verdadero bien de la persona; y este bien "es establecido, como ley eterna, por la sabiduría de Dios, que ordena todo ser a su fin. Esta ley eterna es conocida tanto por la razón natural del hombre (y, de esta manera, es 'ley natural'), cuanto, de modo integral y perfecto, por medio de la revelación sobrenatural de Dios (y por ello es llamado 'ley divina')" (VS 72). En consecuencia, "el obrar humano no puede ser valorado moralmente bueno solo porque sea funcional para alcanzar este o aquel fin que persigue, o simplemente porque la intención sea buena [...] Si el objeto de la acción concreta no está en sintonía con el verdadero bien de la persona, la elección de esa acción hace moralmente mala a nuestra voluntad [...y] nos pone en contradicción con nuestro fin último, el bien supremo, es decir, Dios" (VS 72).

De aquí se sigue que el respeto a la dignidad de la persona es el respeto a su verdadero bien, que se expresa en su naturaleza específica; el verdadero bien de la persona es "una verdad de carácter ontológico" (DP 5), "está inscrita en la naturaleza, y sus leyes siguen siendo norma no escrita a la que todo debe remitirse" (DP 6). Solo las acciones que se conforman a esa norma salvaguardan la dignidad de las personas. En definitiva, el respeto a la dignidad significa salvaguardar la especificidad de los actos

17 "Ciertamente la vida del cuerpo en su condición terrena no es una valor absoluto para el creyente" (EV 47), y "La vida física, por la que se inicia el itinerario del ser humano en el mundo, no agota en sí misma, ciertamente, todo el valor de la persona, ni representa el bien supremo del hombre llamado a la eternidad" (DV Introd 4). 
humanos; por lo que la antropología o la adecuada comprensión de la naturaleza humana termina siendo la única referencia cierta para el juicio moral (cf. DV Introd.).

En concreto, en lo que se refiere a las acciones relativas a la trasmisión de la vida, el respeto a la dignidad implica tanto "el respeto incondicional debido a cada ser humano" como "la tutela de la especificidad de los actos humanos que transmiten la vida" (DP 10). De aquí que los procedimientos e intervenciones biomédicas reciban su valoración moral por su relación con la dignidad de la persona (cf. DP 12), lo que en la práctica significa que solo serán lícitas las técnicas que ayuden o faciliten a que el acto específicamente humano llegue a realizarse; y no serán lícitas cuando, por el contrario, sustituyan o impidan la realización de ese acto (cf. DV B 6). Cuando el acto humano es pervertido o reemplazado por medios técnicos, "la procreación queda privada de su perfección propia" (DV B 4) y se viola la dignidad de la persona.

\section{Matar y dejar morir}

La vida es siempre un bien y nadie puede atribuirse el derecho de matar de modo directo a un ser humano inocente. La razón última de esta norma moral es que matar a una persona inocente es el mayor atentado a su dignidad, es disponer de ella como de un objeto; tratarla como un inferior y decidir de modo voluntarista cuándo y cómo poner fin a su vida. En otras palabras, el respeto que se debe a su vida se funda en el respeto que se debe a su dignidad.

La relación entre estos dos objetos se aprecia a la luz del debate respecto de la eutanasia. La reflexión bioética ha mostrado que matar no es lo mismo que dejar morir, y que si bien matar se califica siempre como una acción moralmente mala, dejar morir no es siempre un mal moral ${ }^{18}$. Al contrario, existen circunstancias en las que el respeto a la dignidad se manifiesta, precisamente, en permitir que la persona muera, en "la renuncia a medios extraordinarios [... que] expresa la aceptación de la condición humana ante la muerte" (EV 65).

18 No pretendo hacer aquí una analogía entre dejar morir a los embriones criopreservados y dejar morir a un enfermo terminal. Por el momento solo busco mostrar que existen casos en el respeto a la dignidad implica no salvar la vida; es decir, que el Magisterio ya ha advertido que la vida no es un bien absoluto que deba protegerse a cualquier costo. 
La distinción entre matar y dejar morir se ha profundizado en los últimos años con el análisis del llamado encarnizamiento terapéutico, o aquellas intervenciones médicas ya no adecuadas para la situación real del enfermo (EV 65) y que reflejan una mentalidad que "recurriendo a cualquier forma de tecnología se afana por programar, controlar y dominar el nacimiento y la muerte" (EV 22). Paradójicamente, el intento voluntarista de determinar el momento de la muerte de una persona es una violación al respeto a la vida que se debe a todo ser humano desde su concepción hasta su muerte natural: Es un atentado contra la dignidad de esa persona cuya misma muerte está siendo dispuesta (decidida) por un tercero. Este caso muestra que, en el fondo, el respeto a la vida nunca se opone propiamente al respeto a la dignidad. Aunque en apariencia pudiera parecer que es así, la misma dignidad es la que exige que en algunas ocasiones a una persona se la deba dejar morir. En estas situaciones se sigue respetando la vida; en concreto, se respeta su término natural, y no se busca extenderla de modo artificial hasta que un tercero determine su final.

Por consiguiente, omitir salvar una vida que naturalmente está muriendo, y que no puede ser salvada si es que no es a través de medios extraordinarios y desproporcionados, no es una falta al respeto a la vida de esa persona sino una afirmación del respeto a su dignidad: a su indisponibilidad $^{19}$.

\section{Rescate de embriones}

Teniendo ya el criterio seguro para analizar la licitud moral del rescate de embriones criopreservados a la luz de las enseñanzas del Magisterio, es necesario definir el objeto, fin y circunstancias de esa acción. El objeto es el elemento central para determinar la licitud moral de una acción, y

19 Una omisión se da cuando un agente puede cambiar y no cambia el curso natural de los acontecimientos. La omisión puede ser culpable, cuando se omite algo que se puede y se debe hacer, en cuyo caso dejar morir equivale a matar (cf. R.G. FrEY, "Acts and Omissions" en L. BECKer y C. BECKER (eds.): The enciclopedia of ethics [Garland, NY, 1992] 14). Por ejemplo, el curso natural de los acontecimientos lleva a que un niño que está creciendo, en la medida en que se nutre, siga creciendo. Si es posible darle de comer y no se hace (se omite dar de comer y se deja que muera de inanición), la acción es moralmente ilícita. Si, por el contrario, el curso natural de los acontecimientos lleva a que un niño con una grave enfermedad esté muriendo, y no es posible evitar su muerte (salvo alguna intervención que viole la dignidad del niño), esa omisión no solo no es culpable sino que constituye un deber moral. 
este se define como el "fin próximo" de la acción (VS 78), aquello que se está haciendo propiamente: la intención que informa tales o cuales movimientos externos de un agente. El objeto no es un proceso o un evento de orden físico solamente, que se valora en cuanto origina un determinado estado de cosas en el mundo exterior (cf. VS 78), sino que corresponde a la acción que se está realizando, es el quése está haciendo, el significado de esos movimientos intencionales ${ }^{20}$.

La intención (o fin) es el para quése realiza la acción, el estado de cosas deseado o el motivo último de ella. Una mala intención del agente convierte en ilícita cualquier acción; pero una buena intención no cambia el valor moral de la misma. Una acción mala -con un objeto ilícito- no deja de ser mala porque se pretendan las mejores consecuencias (cf. VS 72).

Las circunstancias son los diversos elementos contingentes que caracterizan a una acción particular, tanto respecto de quién es el agente, de qué modo moral actúa, el contexto en qué lo hace, etc. Por último, como ya vimos, solo se ordena al verdadero bien de la persona aquello que respeta los elementos esenciales de la naturaleza humana (cf. VS 78); y se considera un mal intrinseco, no ordenable a Dios, todo lo que no da el respeto debido a la persona, "todo lo que ofende su dignidad humana" (VS 80).

\section{La FIV}

\section{Evaluación moral}

El Magisterio ha condenado la FIV por la separación del significado unitivo y procreativo del acto sexual, que traiciona la naturaleza del amor y viola la dignidad del niño que "tiene derecho a ser concebido, llevado en las entrañas y traído al mundo y educado en el matrimonio" (DV A 1). La separación de esferas es solo un aspecto del mal de la FIV puesto que, al tiempo que sustituye la especificidad de un acto humano por una acción técnica, viola también la dignidad del embrión desde que su concepción tiene lugar "por medio de gestos de terceras personas, cuya competencia y

20 A. Gómez-Loвo habla del "fin central inmediato", el objetivo central de los movimientos. Por ejemplo, si un médico está operando una apendicitis y se le pregunta "qué estás haciendo" no dirá: "estoy cortando la piel”, ni tampoco "estoy devolviéndole la salud a esta persona" sino "estoy haciendo una apendicectomía” (Los Bienes Humanos [Mediterráneo, Santiago de Chile, 2006] 74). 
actividad técnica determina el éxito de la intervención; confía la vida y la identidad del embrión al poder de los médicos y los biólogos, e instaura un dominio de la técnica sobre el origen y sobre el destino de la persona humana. Una tal relación de dominio es en sí contraria a la dignidad y a la igualdad que debe ser común a padres e hijos” (DV II B 5).

Además, y "[m]ás allá del hecho de que [las técnicas de fecundación artificial sean] moralmente inaceptable[s] desde el momento en que separa[n] la procreación del contexto integralmente humano del acto conyugal", ellas dan pie a "nuevos atentados contra la vida". Por ejemplo, cuando proporcionan embriones supernumerarios para que sean utilizados en investigación y, con ello, "reduce[n] en realidad la vida humana a simple material biológico del que se puede disponer libremente" (cf. EV 14). Por consiguiente, junto con la perversión de la especificidad del acto sexual humano y la violación de la dignidad en el momento de la concepción de una persona (en cuanto es tratada como un objeto, un inferior respecto de los técnicos que lo producen), la FIV también expone a los embriones a nuevos abusos puesto que tras producir un embrión in vitro se debe hacer algo con él. Es decir, esa persona deberá necesariamente volver a ser tratada como un objeto, ya que de acuerdo con la voluntad arbitraria de un tercero será implantada, desechada, criopreservada, eventualmente después rescatada... Esto es lo que genera una situación aporética, en la que no hay salidas lícitas para la supervivencia del embrión, y en la que las "técnicas de reproducción artificial, que parecían puestas al servicio de la vida y que son practicadas no pocas veces con esta intención, en realidad dan pie a nuevos atentados contra la vida” (DP 14).

En síntesis, la razón última por la que el Magisterio condena la FIV es porque no respeta la dignidad de las personas. No respeta la de los padres, al pervertir la especificidad de la unión sexual plenamente humana, ni tampoco respeta la dignidad del hijo concebido ya que "nadie puede subordinar la llegada de un niño al mundo a condiciones de eficiencia técnica mensurables bajo parámetros de control y dominio" (DV B 4). La FIV atenta flagrantemente contra la indisponibilidad de la persona humana.

\section{El proceso de la FIV}

En general, cuando se habla de la FIV se menta al proceso completo que implica la concepción de una persona in vitro y su transferencia al 
útero materno. Para efectos de claridad, sin embargo, aquí hablaré de la "FIV en sentido estrecho" para referirme a la fertilización in vitro propiamente; y del "proceso de la FIV", que incluye una serie de acciones sucesivas y distintas entre sí en cuanto están conformando un único plan intencional. Las acciones que constituyen este proceso, y que son por separado acciones plenas, también pueden darse fuera del proceso y pueden, en consecuencia, ser evaluadas independientemente de acuerdo con su propio objeto, fin y circunstancias. Por ejemplo, la obtención artificial de gametos no requiere que estos luego se unan en una probeta; la fecundación y generación de embriones (FIV en sentido estrecho) tampoco está intrínsecamente unida a la transferencia al útero materno -los embriones obtenidos pueden también ser desechados, implantados en terceras personas, etc.-; y la transferencia tampoco requiere, como condición necesaria, un embrión producido por FIV ${ }^{21}$. Naturalmente, cuando todas estas acciones están conformando un único proceso basta que una de ellas sea mala para que el proceso se vicie por completo, aun si las otras acciones que lo constituyen fueran indiferentes.

Dos acciones de este proceso interesan particularmente para el análisis ético del rescate de embriones: la unión de gametos (la FIV en sentido estrecho) y la transferencia del embrión al útero de una mujer. Estas acciones son distintas e independientes entre sí, y cada cual puede juzgarse de acuerdo con su propio objeto. La primera es la que el Magisterio ya ha sancionado como intrínsecamente mala por la separación de los aspectos unitivo y procreativo del acto sexual, así como por la violación a la dignidad del niño concebido. Pero la segunda acción es la que más importa para dilucidar la licitud moral del rescate, puesto que este es precisamente 'la acción de transferir y gestar un embrión criopreservado abandonado en el útero de una mujer que no es su madre genética'.

En primer lugar hay que notar que la transferencia no ayuda o facilita la implantación de un embrión concebido en el útero materno, sino que sustituye el movimiento natural con el que la implantación se realiza. En el caso del llamado rescate debe, en primer lugar, existir un embrión no propio congelado. Luego, en sustitución a su movimiento por la trompa de Falopio hacia útero, un técnico lo debe sacar del congelador, descongelarlo e introducirlo en el útero de una mujer que no es su madre.

21 No es impensable que, en el futuro, se pueda transferir un embrión concebido naturalmente desde el útero de la madre al de otra mujer para que lo geste. 
La transferencia, en sí misma, no busca ayudar a que una persona (el embrión en este caso) siga el curso natural de su desarrollo -que es el estándar para establecer la licitud moral de una técnica biomédica- sino que es una nueva manipulación de la persona ${ }^{22}$. La persona (el embrión) debe ser "cogida" del hábitat antinatural en que fue puesta (congelador), descongelada y depositada en el útero de una mujer que no es su madre para ser gestada por esa persona extraña. Esta es la situación aporética a que se ve expuesto un embrión criopreservado abandonado, pues solo podría salvar su vida si nuevamente se viola su dignidad, si se vuelve a disponer de su persona: ser trasladado o no según la voluntad deliberada de un tercero desde el congelador al útero de una mujer que no es su madre. Este es un atentado a la indisponibilidad de una persona, un ejemplo de tratarla como cosa. La decisión de transferir (que es su única opción de vida), cuándo hacerlo, cómo hacerlo, y a quién implantárselo, está en manos de un igual que se pone en el lugar de un superior para definir el destino de ese ser humano ${ }^{23}$.

En consecuencia, el objeto de la acción de la transferencia es distinto al de la "FIV en sentido estrecho", pero es igualmente ilícito ya que

22 H. Watt dice que la transferencia es semejante a un embarazo ectópico en el que el médico debe intervenir técnicamente para "poner" al embrión en el útero $(\mathrm{H}$. WАTT, "Are there any circumstances in which it would be morally admirable for a woman to seek to have an orphan embryo implanted in her womb?", citada por BONET, "El debate", 512). Sin embargo, a mi entender la analogía se equivoca. En el segundo caso sí se ayuda o facilita (no se sustituye) a que el embarazo natural siga su curso. Watt afirma que en el rescate el embrión es fabricado (acción ilícita), es congelado (acción ilícita) y luego "es puesto en el útero". Como identifica este "poner" con el procedimiento que se realiza en un embarazo ectópico, considera que la transferencia es una acción lícita.

23 El técnico que realiza materialmente la transferencia se pone en una posición de superioridad respecto del embrión, como también la mujer (o pareja) que decide rescatarlo o adoptarlo "para salvarle la vida". Estas personas, a pesar de su buena intención, se transforman en sus benefactores o salvadores, y rompen así la igualdad esencial entre ellos y el niño. Su buena voluntad es la que da la opción de vida a esa persona, la que quedará para siempre en deuda con sus rescatistas. El caso es análogo a la adopción de niños ya nacidos "por razones humanitarias" que -como se estudia en psicología- se sienten inevitablemente como "niños en peligro", y tanto su identidad como su autoimagen son amenazadas por esa sensación de inferioridad y deuda (cf. P. EgENAU y otros, El proceso de ser padres adoptivos [Editorial Nueva Patris, Santiago de Chile, 2013] 72). 
también viola la dignidad de una persona. Y si el objeto de la acción es ilícito, la acción es intrínsecamente mala.

Por cierto, si el embrión no es transferido el embrión muere; razón por la cual muchos estudiosos afirman que hay que optar por el mal menor. No obstante, en esto la doctrina de la Iglesia es clara: Jamás se puede optar por un mal menor porque eso significa intencionar un mal: Elegir deliberadamente hacer un mal, una acción contraria a la naturaleza del hombre y no ordenable a Dios (DP 21). Existen al menos dos causas que inclinan a aprobar este procedimiento. Una de ellas es que el mal menor es uno de los elementos esenciales de las éticas proporcionalistas y consecuencialistas que priman en nuestra cultura y que muchas veces, sin que nos percatemos, permean nuestros juicios. Y la segunda es la gran fuerza psicológica que impone el respeto a la vida. No obstante, aquí nos encontramos frente a otro de esos casos en los que se debe distinguir entre el respeto a la vida, entendido como el imperativo de salvarla a cualquier precio, y el respeto a la dignidad; y en los que se debe recordar que el primero no es absoluto mientras que el segundo es irrenunciable. En la EV se afirma que Dios dio al hombre "el dominio confiado" de la creación, pero este "no es un poder absoluto. La limitación impuesta por el mismo Creador desde el principio, [fue] expresada simbólicamente con la prohibición de 'no comer del fruto del árbol' [del bien y del mal]" (EV 42). Es decir, el hombre no puede arrogarse el derecho a decidir cuál es el bien o el mal, sino que debe seguir el orden establecido por Dios, el de la ley natural que refleja la ley divina: Jamás será lícita (ni siquiera en cuanto menos mala) una acción que realiza directamente un mal.

Por tanto, si la transferencia del embrión es una acción ilícita, la conclusión es que la única acción moralmente lícita frente a los embriones criopreservados abandonados es no transferirlos y no volver a violar su dignidad $^{24}$. Si esto nos parece contraintuitivo es porque no nos resulta evidente que esos embriones sean personas, y la mentalidad eficientista

24 "No transferirlos" significa dejarlos morir. En la Segunda Parte discutiré por qué este no es un dejar morir ilícito (una acción intencional que equivale a matar directamente). Por el momento, baste pensar en que se les puede dejar morir dentro del congelador en que otros los pusieron, solo esperando que esa vida que está artificialmente "suspendida" pueda al fin terminar (cf. T. PACHOLCZYK, "What should we do with the frozen embryos?" en http://www.catholiceducation.or/ articles/medical_ethics/me0137.htm, 2). También se podrían establecer criterios de muerte presunta para sacarlos del tanque en que están injustamente sumergidos. 
de nuestro tiempo nos lleva a verlos como "cosas" que podríamos llevar a buen término. Pero como todo niño "tiene el derecho [...] a tener un origen plenamente humano, adecuado a su naturaleza personal de ser humano" (DV I 6, n.32), y la violación de su indisponibilidad implica pervertir ese origen y su dignidad, si verdaderamente creemos que el embrión es una persona humana no podemos sino admitir que no existe ninguna vía moralmente lícita para su supervivencia ${ }^{25}$.

\section{Criopreservación}

Un embrión producido vía FIV puede ser implantado, desechado, usado en investigación o criopreservado. Si no es implantado de modo inmediato, la criopreservación es la única alternativa que salva la vida del embrión, manteniéndolo en un congelador en caso de que sus padres decidan, al cabo de un tiempo, tener otro hijo.

Como las opciones son la muerte o la vida del embrión se podría volver a pensar en la doctrina del mal menor. Pero en este caso, y a diferencia con el rescate (y/o adopción prenatal), existe un amplio consenso entre quienes respetan la dignidad de la persona desde su concepción hasta su muerte natural en rechazar este procedimiento. En esta técnica se percibe con nitidez la violación de la dignidad de la persona del embrión, de quien se está disponiendo de un modo patente: Se le impide su desarrollo, se le pone en un habitat totalmente ajeno a su naturaleza humana, y se decidirá arbitrariamente por la voluntad de terceros cuándo podrá nacer - si acaso ello se le permite ${ }^{26}-$.

La criopreservación es otra de las situaciones en las que el respeto a la vida y el respeto a la dignidad parecen separarse. Y quienes condenan

25 Se puede pensar en un ejemplo que pone en evidencia la importancia de la dignidad. Si un niño de dos años tiene una enfermedad que necesariamente lo llevará a la muerte salvo que, durante un mes, sea sistemáticamente violado por un grupo de pedófilos. Incluso si al niño se lo anestesia para que no se dé cuenta de lo que está pasando, difícilmente aceptaríamos una violación tan grande a su dignidad, aun si ello implicase dejarlo morir.

26 Mattheeuws señala que al criopreservar se priva a los embriones de una cualidad inherente a su naturaleza humana: la temporalidad (y, con ella, la capacidad de desarrollarse). Los embriones quedan removidos del universo y de toda relación humana; su vida está detenida y "su estado, por naturaleza frágil, es fijado en esa fragilidad" (A. MatTheEuws, "The freezing, implantation and adoption of embryos", http://www.lifeissues.net/writters/matt/matt_01adopembryos.html, 2-3). 
esta práctica no lo hacen por desconsideración al respeto debido a la vida de un ser humano inocente sino porque, al menos intuitivamente, comprenden que la violación a la dignidad sobrepasa cualquier otro derecho.

$\mathrm{Al}$ respecto, y particularmente iluminador para el análisis del rescate de embriones criopreservados abandonados, la Donum Vitae señala: "aunque se realice para mantener en vida al embrión ... constituye una ofensa al respeto debido a los seres humanos, por cuanto les expone a graves riesgos de muerte o de daño a la integridad física, les priva al menos temporalmente de la acogida y de la gestación materna y les pone en una situación susceptible de nuevas lesiones y manipulaciones" (DV I 6. Cursivas mía). En este pasaje se afirman dos elementos que serán centrales para argumentar la ilicitud moral del rescate:

Primero, la DV ratifica que el bien de la vida no es absoluto y no puede mantenerse a costa de la dignidad de una persona. La dignidad es el único bien irrenunciable frente a los que cualquier otro bien, incluso el de la vida, debe ceder. Por esto es que aunque se podría pensar que comparada con "desechar" la criopreservación es un mal menor, como el objeto de la acción es ilícito la acción se vuelve intrínsecamente mala.

Segundo, en este pasaje la DV explicita que lo adecuado o lo que corresponde al embrión humano -aquello de lo que es injusto privarlees la gestación materna, i.e. la gestación del embrión en las entrañas de su madre genética (hasta el momento de su criopreservación no hay ninguna otra mujer a la que se la pudiera también llamar madre). La DV no habla genéricamente de que se "les priva de ser gestados". Es más, en el mismo acápite se condena la gestación de embriones humanos en úteros animales así como "la construcción de úteros artificiales para el embrión humano" porque "estos procedimientos son contrarios a la dignidad de ser humano propia del embrión y, al mismo tiempo, lesionan el derecho de la persona a ser concebida y a nacer en el matrimonio y del matrimonio" (DV I 6).

En consecuencia, de lo anterior se puede concluir que, para el Magisterio, (a) "salvar la vida" no es suficiente razón para violar la dignidad de un embrión; y también que (b) esa dignidad se vería lesionada en una gestación heteróloga, es decir, cuando no es la propia madre quien gesta al embrión. Si la DV no condenara la gestación heteróloga no habría razón para reprobar la gestación del embrión por algún otro medio que 
le proporcione el soporte o las condiciones físicas adecuadas para su desarrollo prenatal ${ }^{27}$.

El rescate: objeto, fin y circunstancias

El rescate de los embriones criopreservados es una acción totalmente diversa de las otras acciones involucradas en el proceso de la FIV. Esta además se realizaría por quienes se oponen tanto a al FIV como a la criopreservación, y su intención sería rectificar en la medida de lo posible todas las violaciones a la dignidad a las que el embrión se ha visto sometido. Las mujeres que se embarazan de estos embriones abandonados no han participado ni aprueban la FIV que los concibió, y su motivación es salvarles la vida; ofrecerles, en un acto de solidaridad, la única posibilidad que tienen para nacer ${ }^{28}$.

En esta acción el fin (la intención de las rescatistas) es el respeto debido a la vida de todo ser humano inocente. Las circunstancias incluyen el que estos son embriones abandonados, que de otro modo serán desechados, que se está violando su dignidad y, en suma, todos los aspectos contingentes que caractericen la situación particular en la que se tome la decisión de embarazarse con alguno(s) de ellos. Y el objeto de la acción es la transferencia y gestación de un embrión criopreservado abandonado en el útero de una mujer que no es su madre genética. En otras palabras, una mujer decide deliberadamente transferir y gestar en su propio útero un embrión heterólogo para salvarle la vida.

Como ya vimos que el objeto de la acción de la transferencia es intrínsecamente malo en cuanto viola la dignidad del embrión, el rescate también debe calificarse como intrínsecamente malo $^{29}$. Por tanto, y a pesar de la buena intención de las rescatistas, su acción es moralmente ilícita.

27 En DP 18 la doctrina se reafirma al declarar la incompatibilidad de la criopreservación con el respeto debido al embrión, y se repiten los argumentos insistiendo en hablar de gestación materna.

28 Para recomponer un mal que ya se hizo se apela a una evaluación global de la acción y al principio de solidaridad.

29 Aunque el rescate pueda también entenderse como un proceso que implica una serie de acciones, basta que una de las acciones que componen el proceso sea intrínsecamente mala para que el proceso entero sea moralmente ilícito (es decir, la posible bondad de las otras acciones no anula la maldad de la transferencia). 
Por otro lado, en el rescate de embriones el mal de la acción de la transferencia aumenta en cuanto es un embarazo heterólogo. El Magisterio condena explícitamente la fecundación heteróloga, arguyendo que "el hijo tiene derecho a ser concebido, llevado en las entrañas, traído al mundo y educado en el matrimonio [ya que] solo con esa referencia conocida y segura a sus padres pueden los hijos descubrir la propia identidad y alcanzar la madurez humana" (DV A 1). Pero esta sentencia es lógicamente extensible a todo embarazo heterólogo puesto que ser "llevado en las entrañas, traído al mundo y educado" trasciende el momento exacto de la fecundación.

Además, cuando la DP condena la adopción prenatal lo hace por "las mismas razones que hacen ilícita tanto la procreación artificial heteróloga como toda forma de maternidad subrogada" (DP 19). Y lo que estas tres prácticas tienen en común es, precisamente, el embarazo heterólogo, que "manifiesta una ruptura entre la paternidad genética, la gestacional y la educativa. Esta alteración de las relaciones personales en el seno de la familia tiene repercusiones en la sociedad civil: lo que amenace la unidad y la estabilidad de la familia constituye una fuente de discordias, desórdenes e injusticias en toda la vida social” (DV II A 2) ${ }^{30}$.

Sobre este punto, L. M. Pastor comenta que en DP 19 se empieza a ver el desarrollo de un tema nuevo, a saber, el deber de la no disyunción entre la maternidad genética y biológica o "la existencia de un bien primario de carácter antropológico al cual toda mujer estaría ligada: la de solo ser gestante de aquel ser humano generado de su propio marido y que ha sido engendrado en ella misma. Estaríamos ante dos dimensiones o aspectos de la maternidad esenciales que conformarían un bien que la mujer debe respetar siempre y que además supone una exigencia respecto del propio cónyuge" 31 . En otras palabras, Pastor vislumbra en este pasaje de la DP la explicitación de un nuevo criterio moral, análogo al deber de la no disyunción de las esferas unitiva y procreativa del acto sexual, al que el Magisterio estaría llegando ante el desafío que estas nuevas posibilidades biomédicas ofrecen. Y aunque Pastor centra este criterio en un bien propio de la madre, su contracara obviamente es el

30 Se debe recordar que el rescate no es lo mismo que la adopción prenatal, pero en ambos casos se da una ruptura entre la paternidad genética y la gestación, con iguales consecuencias.

31 L. M. Pastor, “Análisis...”, 40-41. 
bien del embrión, y su derecho de ser engendrado y gestado en las entrañas de su propia madre.

De esto se sigue que el rescate de embriones criopreservados es una acción intrínsecamente mala, tanto por la violación de la indisponibilidad de la persona del embrión que se da en la transferencia como, para mayor abundamiento, porque por definición implica un embarazo heterólogo. Ambos aspectos transgreden "el legítimo ... derecho del niño a tener un origen plenamente humano a través de la concepción adecuada a la naturaleza personal del ser humano" (DV I 6 n32). Estas dos características, que se funden en la definición del objeto de la acción del rescate, son contrarias al bien integral de la persona y no se pueden ordenar a Dios. Por tanto, el rescate no es una práctica que se pueda permitir. Su objeto es malo, viola la dignidad de una persona, y la buena intención de la mujer que está dispuesta a gestarlo no cambia la calificación moral del hecho.

Finalmente, esta conclusión acerca del rescate de embriones criopreservados es extensible a la adopción de los mismos, puesto que si bien hay diferencias en las circunstancias y, eventualmente, en el fin o intención de los adoptantes (salvar una vida y/o formar una familia), el objeto de la acción (la transferencia y gestación de embriones criopreservados abandonados en el útero de una mujer que no es su madre genética) sigue constituyendo la misma ofensa en contra de la dignidad de los embriones.

\section{SEGUNDA PARTE}

A pesar de que una acción intrínsecamente mala no puede volverse buena por una buena intención ni ningún tipo de circunstancias, es útil conocer los argumentos que se dan para apoyar el rescate y/o adopción de embriones criopreservados y establecer sus problemas. Lo primero que hay que destacar es que, como ya se dijo, este no es un debate zanjado dentro de la Iglesia, lo que permite que existan posturas contrapuestas con argumentos que aluden a diversos aspectos de esas prácticas para defender o rechazar su licitud moral. Este tipo de discusiones resulta muy conveniente para ponderar con la mayor inteligencia y claridad el significado antropológico de ciertas prácticas, y discernir si están o no en consonancia con la especificidad de los actos humanos y si hacen justicia a la dignidad de la persona. 
Muchos pensadores cristianos defienden la licitud de este tipo de gestación heteróloga. Algunos piensan que la adopción prenatal es la única alternativa moralmente aceptable para los embriones criopreservados abandonados; otros creen que como la adopción y el "dejar morir" son alternativas inaceptables desde una perspectiva católica, solo quedaría el rescate; y finalmente, muchos se inclinan por la adopción aunque admiten también la posibilidad del rescate como una última opción frente a la muerte del embrión.

En esta Segunda Parte revisaré los argumentos de estos autores para defender la licitud moral de estas prácticas. De acuerdo con mi análisis existen tres aspectos que presentarían problemas. El primero se relaciona con el respeto a la vida, que es la principal razón por la que defienden la licitud del rescate/adopción prenatal pero que terminan subordinándolo a otras consideraciones. El segundo es una mala identificación del objeto de la acción del rescate/adopción prenatal, de lo que naturalmente se siguen conclusiones erradas. Y por último, el proporcionalismo ético que subyace en muchos razonamientos.

El respeto a la vida

El argumento central de estos autores para defender el rescate/adopción prenatal es el respeto que se debe a la vida de todo ser humano inocente. Afirman, por una parte, que el derecho a la vida es el principal derecho de toda persona ${ }^{32}$ y una verdadera fuente de obligatoriedad y eticidad ${ }^{33}$, y que este tipo de gestación heteróloga protegería la vida más que violar$1 a^{34}$. También señalan que salvar a estos embriones tendría un valor testi-

32 Lucas dice que "el criterio que rige es el bien primario y principal: la vida del embrión" (R. LUCAS, "La criopreservación de embriones: Una interferencia abusiva”, Alfa y Omega, 24.07.2003); Furton también señala que la adopción sería "en algún sentido la única opción moral" ("On the disposition...”, 2).

33 Cf. M. Cozzoli, "L’embrione umano: aspetti ético-normativi”, en AA.VV. Identità e statuto dell'embrione umano (Librería Editrice Vaticana, 1997), 237-273. El autor defiende la adopción prenatal afirmando que "La verdad de la persona del embrión humano es fuente de eticidad" (nótese que, precisamente por la misma razón, en la Primera Parte he argumentado que toda gestación heteróloga -incluyendo el rescate/adopción- es ilícita).

34 G. GRISEZ, "Should a woman...", 242. El autor continúa: "Puesto que una nueva persona ya existe, no violaría la trasmisión de la vida”. Sin embargo, mi argumento es que si bien no la viola en cuanto a la FIV en sentido estrecho, la acción de 
monial: mostrar al mundo el valor de una vida humana ${ }^{35}$. Sin embargo, no todos coinciden respecto de cuál es el mejor modo de honrar el bien de la vida. Hay tres opciones:

a) Solo adopción:

Quienes se inclinan por la adopción prenatal afirman que dado que estos embriones ya existen, se debe encontrar "la mejor imitación al modelo natural"36. Asimismo, hay autores que señalan la obligación de adoptar en cuanto la adopción exalta el sentido humano como apertura a la vida ${ }^{37}$. Por otro lado, estos autores rechazan el rescate afirmando que este produciría un mal al embrión. Ya habiendo sido abandonados por sus padres genéticos, volver a ser abandonados por su madre gestacional sería profundizar en el mal que ya sufrieron. Rescatar sin adoptar implicaría dar a luz niños huérfanos.

b) Solo rescate:

Otro grupo de autores piensa que la adopción no puede ser lícita en cuanto podría constituirse en una "vía católica para las parejas infértiles"38, que es precisamente lo que no admite DP 19. Por esto se distingue la transferencia de embriones para salvar una vida de la transferencia

la trasferencia y gestación heteróloga siguen siendo parte del proceso de rescate/ adopción, y sí viola la dignidad del embrión.

35 Cf. E. Bonet, "El debate...", 499: "El deshacerse indiscriminado de miembros de nuestra especie, tendría un impacto negativo en la percepción social del valor de la vida humana”. Esta posición, en este lugar atribuida a otros autores, es suscrita también por él en págs. 534-535.

36 Así lo sentencia el Comitato de Bioética de Verona, 2000; citado por BonET, "El debate...", 504.

37 Cf. M. FagGioni: "Una vez que los embriones son concebidos in vitro, existe por cierto la obligación de transferirlos a la madre y solamente ante la imposibilidad de hacerlo de inmediato se podrían congelar, siempre con la intención de transferirlos apenas se hayan presentado las condiciones" (M. FAGGIONI, "La cuestión de los embriones congelados: Una lógica de muerte”, L'Osservatore Romano, 23.07.1996. Cf. http://www.arbil.org/(32)embr.htm, 4).

38 Cf. C. M. Young, "The ethics of frozen embryo transfer. A moral study of embryo adoption”, Universitá Della Santa Croce, Roma, 2005, citada por BonET, "El debate...", 515. De acuerdo con Young (y otros autores como M. Geach) aceptar la licitud de la adopción prenatal, i.e. embarazarse de un embrión criopreservado abandonado con una intención reproductiva, se podría convertir en una técnica de reproducción artificial legitimada por la Iglesia (o, al menos, podría parecer tal). 
de embriones para superar la infertilidad ${ }^{39}$, aceptando solo la primera alternativa.

c) Adopción o rescate:

Finalmente, la mayoría de los autores se inclinan por la adopción, pero admiten que el rescate sería la extrema ratio ${ }^{40}$. Si la mujer que gesta al niño no puede hacerse cargo de él, no sería ilícito que lo diera en adopción. Sin ser lo ideal, no es tampoco la mejor opción.

\section{Discusión}

Estas tres opciones de justificación de gestación heteróloga presentan problemas. El más importante, que atañe a las dos primeras, se relaciona precisamente con el "bien primero y principal" que se busca defender y el "valor testimonial" que tendría este tipo de prácticas. En efecto, si el valor de la vida es "primero y principal", no es lógico que deba supeditarse a la posibilidad de que la persona que se ofrece para gestarlo se comprometa a darle una familia bien constituida (i.e. que no se permita el rescate) o a la de que, por el contrario, la persona que se ofrece para gestarlo se comprometa a no quedarse con él (i.e. que no se permita la adopción). Si el argumento para aceptar este tipo de embarazo heterólogo es el de su valor testimonial -en cuanto honraría el valor de la vida- las restricciones a quienes pueden embarazarse lo devaluarían. En otras palabras, si la vida es primero, las otras consideraciones deberían subordinarse a ella y no al revés. Cuando se salvaguarda la vida solo en la medida en la que no se violen otros bienes, el bien de la vida deja de ser el principal argumento para promover este tipo de embarazos.

El tercer grupo de autores piensa que la adopción de embriones criopreservados abandonados por parte de familias bien constituidas es lo ideal pero que, en última instancia, también se podría aceptar que

39 Discutiendo este argumento, Bonet comenta que el hecho de que la gestación adoptiva incluya el deseo reproductivo no la hace ilícita, diciendo que la supuesta ilicitud provendría del "sentido generativo" de la reproducción (la FIV) y no su "sentido adoptivo" ("El debate..., 540). Lo fundamenta en las alabanzas que el Magisterio hace de la adopción convencional. Sin embargo, habría que confrontar con DP 19 y su condena explícita de la adopción prenatal de embriones donados, lo que claramente implica que no fueron encargados. Es decir, DP 19 no puede estar condenando exclusivamente la concepción por encargo.

40 M. FAGgioni, "Una lógica...”, 5. 
otras mujeres (solteras, parejas lesbianas, parejas infértiles...) rescataran/ adoptaran a esos embriones. Afirman que aunque estos casos son desaconsejables y podrían ser imprudentes, ante la escasez de parejas bien constituidas habría que permitir que estos embriones vivieran a pesar de no poder darles una familia adecuada. Esta postura es más consistente que las dos anteriores respecto del valor principal que se le da a la vida de los embriones, sin embargo, si se analiza a la luz de las enseñanzas del Magisterio se ve que también conlleva problemas -que son, precisamente, los que las otras dos posturas intentan evitar. En primer lugar, si se da el caso de la adopción, se estaría aceptando la "intención reproductiva" que es explícitamente rechazada por DP 19. Y en segundo lugar, si se da solo el rescate, se estaría aceptando que al embrión que ya se le privó del derecho a "ser concebido en el matrimonio y dentro del matrimonio", se le prive ahora también de los derechos a "ser llevado en las entrañas, dado a luz y educado en el matrimonio y dentro del matrimonio".

Finalmente esta última posición evidencia el problema de fondo en toda defensa de esta clase de gestación heteróloga. Si la vida es el bien que se debe preservar a toda costa, ¿cómo se explica el rechazo explícito del Magisterio a la gestación del embrión en, por ejemplo, úteros artificiales? Incluso si esos embriones ya hubiesen sido adoptados antes de comenzar a desarrollarse en un útero artificial, la Iglesia condena esa práctica $^{41}$. La vida no es un bien que haga ceder a cualquier otro.

\section{Descongelar: Matar o dejar morir}

Si el embrión criopreservado no es transferido al útero de una mujer (o eventualmente a un útero artificial) ese embrión muere, pues todavía no tiene la capacidad de crecer y desarrollarse por sí mismo. De ahí que cuando se defiende el derecho a la vida de todo ser humano inocente surja naturalmente la discusión sobre si la muerte de ese embrión sería un caso de matar o de dejar morir.

Como ya se adelantó, en las últimas décadas ha habido un extenso desarrollo de la distinción de estas nociones dentro del ámbito de la bioética, en particular en torno al debate sobre la eutanasia. Esta pre-

41 E. Bonet afirma que "una vez co-creada la persona en el ámbito de una donación conyugal, [la gestación] pertenece al ámbito del necesario soporte físico y nutritivo para el crecimiento del embrión" ("El debate...”, 534). Esta afirmación es difícil de conciliar con la condena de la Iglesia a los úteros artificiales. 
cisión conceptual permite distinguir y evaluar de manera diferenciada cuándo a un paciente con una enfermedad terminal se le mata (eutanasia) y cuándo simplemente se le deja morir para evitar, por ejemplo, un encarnizamiento terapéutico. Pero la distinción trasciende el ámbito de los enfermos terminales y sus opciones terapéuticas. Su alcance es más amplio que el de lo propiamente médico.

Discutiendo la diferencia entre matar y dejar morir, y aunque su análisis se dirige en última instancia al mismo debate de la eutanasia, D. Sulmasy da definiciones lo suficientemente generales como para que puedan aplicarse a diversos casos. Este autor señala que matar es "el acto por el que un agente origina un [nuevo] estado letal, con la intención específica de causar con este la muerte de una persona”42. Matar implica poner a una persona que no está necesariamente muriendo en un estado en el que sí morirá y hacerlo con la intención de que muera ${ }^{43}$, por lo que, de acuerdo con las enseñanzas del Magisterio, la acción se calificaría como intrínsecamente mala (cf. EV 53). Obviamente es posible que alguien mate a los embriones criopreservados si los saca del congelador con la intención de desecharlos o usarlos para investigación o experimentación.

Ahora bien, ¿es posible aplicar la noción de dejar morir a los embriones criopreservados? Y si así fuera, ¿sería un dejar morir culpable (i.e. equivalente a matar) o un dejar morir no culpable (no objetable moralmente o incluso obligatorio)? Una definición amplia de dejar morir dice que ello consiste en "un acto que un agente realiza una acción que remueve una intervención que previene o mejora una condición fatal preexistente, o bien se refrena de realizar una acción que habría impedido o mejorado una condición fatal, con la intención específica de que su acción provoque la muerte de la persona o sin la intención de que produzca la muerte de la persona" ${ }^{44}$. En este caso, el dejar morir es culpable cuando la intención del agente es que la persona muera, y no es culpable cuando el agente no intenciona (aunque prevea) la muerte de la persona ${ }^{45}$.

42 D. Sulmasy, "Killing and allowing to die", Journal of Law Medicine Ethics 26 (1998) 57.

43 Por ejemplo, disparar en la cabeza a una persona que goza de buena salud.

44 D. Sulmasy, “Killing...”, 58.

45 Hay que recordar que la acción se juzga por su objeto, lo que el agente pretende lograr con los movimientos externos que está realizando; la intención que está 
Aplicadas estas definiciones al caso de los embriones criopreservados, hay quienes dicen que no transferirlos al útero de una mujer (no salvar su vida) es una omisión culpable, puesto que los embriones no están muriendo como un enfermo terminal ${ }^{46}$. Pero aunque es cierto que los embriones congelados no son enfermos terminales, la noción de dejar morir es más amplia que su aplicación a la medicina. Por ejemplo, un astronauta perfectamente saludable pierde su tanque de oxígeno en una caminata espacial: El astronauta no está enfermo y sin embargo se encuentra en una situación fatal. Si nadie lo auxilia, el astronauta morirá. En segundo término, aunque los embriones criopreservados no están muriendo como un enfermo terminal, tampoco están desarrollándose como corresponde a un embrión humano. El enfermo ya no puede realizar las operaciones vitales que le son propias para continuar su desarrollo, pero el embrión criopreservado tampoco puede realizar sus operaciones propias y nunca podrá hacerlo, ni dentro ni fuera del estanque de nitrógeno en el que fue puesto. Así, aunque el embrión criopreservado no está muriendo como un enfermo terminal, su situación se acerca más a esa que a la de un embrión que se desarrolla. Y aunque todavía no se sepa cuánto tiempo puede resistir en condición de "animación suspendida”, sí se sabe que muchos embriones criopreservados están ya muertos y que mientras más tiempo permanezcan en el congelador aumentan las posibilidades de que mueran (por ello algunos recomiendan que se vayan rescatando en el mismo orden temporal en que se fueron congelando). De ahí que se pueda decir que si bien su situación no es (necesariamente) terminal, sí están directamente orientados a la muerte: Si el embrión no es transferido al útero de una mujer, al cabo de los años (sean 50, 500 o 5.000 años) dejará de vivir sin nunca haber podido desarrollarse. Aunque no es un "estar muriendo" en el sentido habitual, lo que definitivamente no es es "estar desarrollándose".

informando la acción concreta que ejecuta y no las consecuencias que prevea ni los estados disposicionales subjetivos con los que la realiza. D. Sulmasy afirma que si bien la medicina prohíbe intencionar la muerte de un paciente, no implica con ello que deba convertirlos en prisioneros de la tecnología que solo "prolonguen su 'estar muriendo"” ("Killing...", 58-59).

46 De acuerdo con A. Cioffi, "descongelar embriones humanos sin el propósito de implantarlos es moralmente equivalente a matarlos activamente" (cf.A. CiofFI (http:// www.hayalternativas.org/Documentos/quehacerconlosembrionescongelados.doc). 
Por último, solo hay omisiones culpables cuando estas cumplen ciertas condiciones, entre las que se cuenta que exista la obligación de actuar y no se actúe ${ }^{47}$. Si transferir el embrión criopreservado al útero de una mujer fuera una obligación moral, la acción de rescatar/adoptar no sería heroica o supererogatoria sino solo justa.

Sí es importante notar que la situación en que se encuentran los embriones criopreservados no es análoga a lo que se llama encarnizamiento terapéutico, ya que los embriones no están ni enfermos ni sometidos a una terapia. Sin embargo que no sea encarnizamiento terapéutico no implica que la transferencia heteróloga sea moralmente lícita. Cada acción debe valorarse de acuerdo con su objeto, y el objeto de acuerdo con el bien integral de la persona. Así, la razón última de la ilicitud del encarnizamiento terapéutico es la violación de la dignidad de la persona (cf. EV 65). Pero la dignidad no es solo la piedra de toque de las terapias curativas, sino también " $[\mathrm{s}] \mathrm{i}$ un programa de cuidados paliativos mina la dignidad intrínseca que da la fuerza vinculante al imperativo moral de otorgar cuidados paliativos, entonces existe un deber de obligación perfecta de no seguir con ese plan" ${ }^{48}$. Del mismo modo, sin ser encarnizamiento terapéutico, si la transferencia de un embrión criopreservado al útero de una mujer que no es su madre genética viola la dignidad del embrión, la obligación moral es justamente la de no realizar esa transferencia.

De lo anterior se sigue que dejar morir al embrión (previendo pero no intencionando su muerte) no es una omisión culpable. Al contrario, es la dramática pero única opción que existe para respetar su dignidad: librarlo de la prisión técnica, devolverlo a la dimensión del tiempo y permitir que su vida termine naturalmente. Y si la opción de sacarlo del tanque de nitrógeno que le retiene en una situación inhumana despertase todavía dudas sobre si es matar, queda la alternativa de no hacer nada y esperar a que muera dentro del mismo congelador ${ }^{49}$.

47 Cf. R. G., Frey, “Acts...”, 14.

48 D. Sulmasy, "Death, dignity and the theory of value", Ethical Perspectives 9/2-3 (2002), 20.

49 T. PAChOlCZYK, "What should...", 2. A pesar de que esta alternativa pudiera parecer menos violenta, podría también interpretarse como una omisión culpable, ya que pudiendo liberarlos de la situación injusta en que se los ha puesto se omite hacerlo. Es la "situación absurda" en que se los puso, la "injusticia irreparable" que sufrieron. 
El objeto de la acción

La calificación moral de una acción depende primariamente de su objeto; ni una intención buena ni unas circunstancias trágicas pueden volver lícita una acción con un objeto malo. El objeto de la acción es, exactamente, esa acción que se está realizando. Y si la acción lesiona la dignidad de una persona, si no es ordenable a Dios, es una acción intrínsecamente mala y siempre, bajo cualquier circunstancia, prohibida. De ahí que sea tan importante acertar en la identificación y la descripción del objeto de la acción realizada: Qué se está haciendo.

En el debate acerca del rescate/adopción de los embriones criopreservados abandonados se ha tendido a confundir el objeto de esa acción con la intención (salvar una vida); a dar una descripción parcial (gestar un embrión heterólogo) e incluso a definirlo en términos negativos, i.e. lo que no es (no es subrogación; no es procreación, no separa los aspectos unitivo y procreativo de la unión sexual). Estos últimos son precisamente los tres puntos que C. Brugger afirma que se deben examinar para establecer la licitud de esta práctica, es decir, revisar si el rescate/adopción prenatal respeta la prohibición de la subrogación; si protege los bienes propios de la unión marital, y si protege los de la procreación humana ${ }^{50}$. Y como el rescate/adopción prenatal no atenta contra ninguno de estos bienes ni viola las normas que los resguardan, Brugger concluye que sería una acción lícita. Sin embargo, de que estos bienes estén protegidos no se sigue que el objeto específico del rescate/adopción prenatal sea bueno.

Según lo que aquí he expuesto el objeto de la acción del rescate (y que, poniendo entre paréntesis la intención del agente, describe también la adopción prenatal) es 'la transferencia y gestación de un embrión criopreservado abandonado en el útero de una mujer que no es su madre genética'. El fin del agente es salvar una vida (en el caso de la adopción puede ser también formar una familia); y las circunstancias incluyen la existencia de embriones criopreservados abandonados, la capacidad de una mujer de embarazarse, las posibilidades técnicas, tal vez la convicción de estar haciendo un bien, etc. Sin embargo, ni el fin loable, ni las circunstancias trágicas, ni la falta de advertencia o eventual ignoran-

50 C. Brugger, "Rescuing frozen embryos: Is adoption a valid moral option?", Culture of Life Foundation. Briefs. March 19, 2010, 5 (http://www.lifeissues.net/ writers/bru/bru_14frozenembryos.html). 
cia invencible de una persona pueden volver una acción materialmente mala en una acción buena ${ }^{51}$.

\section{La relación con el acto conyugal}

Uno de los argumentos que más se repiten en la discusión sobre la licitud del rescate/adopción prenatal es el referido a los bienes propios del matrimonio. Quienes se oponen a esta(s) práctica(s) afirman que ella(s) "desnaturalizaría(n) el acto conyugal" 52 . Señalan que la acción es ilícita en cuanto ofende la dignidad del matrimonio puesto que "la mujer solo puede ser madre a través de su marido" 53 y no puede ser embarazada fuera de esa unión. Y concluyen que tanto el rescate como la adopción serían faltas a la castidad, infidelidad e incluso adulterio. El argumento es que existe una unidad indiscernible entre la procreación y la gestación, y que el acto conyugal en el que marido y mujer se entregan mutuamente para concebir un hijo es más amplio que la mera acción física. De ahí que el rescate/adopción prenatal atentaría contra la especifidad de este acto humano y sería inmoral.

Por su parte, los que defienden el rescate/adopción discuten esta tesis afirmando que procreación y gestación son dos momentos independientes por lo que no cabe aplicar a los rescatadores la inmoralidad de la FIV, tal como nadie imputa a los padres adoptivos la inmoralidad del abandono. La perversión del acto conyugal ya tuvo lugar, y la gestación heteróloga no disocia los fines unitivo y procreativo del acto sexual. De aquí concluyen que no sería una acción intrínsecamente mala ${ }^{54}$.

51 La advertencia implica el saber si la acción que realiza es buena o mala. La ignorancia invencible significa que la persona no sabe que una acción es mala y no tiene ninguna posibilidad de salir de su error. Cuando esto sucede, aunque la persona no es culpable de la acción que realiza pues no sabe ni tiene cómo saber que está haciendo un mal, la acción sigue siendo mala.

52 Entre estos autores destaca N. TonTI-Filippini, "The embryo rescue debate: Impregnating women, octogenesis and restoration from suspended animation", National Catholic Bioethics Quarterly 3 (2003), 111-137.

53 Cf. Familiaris Consortio 14 y 41; DP 12.

54 Por ejemplo, C. Brugger dice "El mal se realizó en la creación, en la FIV; no es la transferencia" ("Rescuing...", 4), y Miranda, "El mal ya está hecho, ahora hay que evitar un mal mayor” (G. MirandA, “¿Se pueden adoptar los embriones congelados?”, http://es.catholic.net/sexualidadybioetica/347/2675/articulo.php?id=8168, 3). 
Pues bien, al margen de si la gestación forma parte o no de la procreación, es cierto que la culpa moral no se traspasa desde quienes realizaron la FIV en sentido estrecho a quienes la rechazan pero buscan actualmente salvar la vida de los embriones abandonados. Asimismo, si procreación es solo el momento de la unión de gametos, también parece claro que el rescate/adopción prenatal es un suceso completamente ajeno a la separación de los aspectos unitivo y procreativo del acto sexual. Sin embargo, el rechazo al rescate/adopción prenatal se debe a que su propio objeto es ilícito, y no a la ilicitud del objeto de la FIV en sentido estrecho. Aunque la transferencia y gestación heteróloga no se relacionaran con el acto conyugal, sí violan la dignidad del niño y eso es lo que lo hace éticamente condenable.

Del mismo modo, tampoco se puede concluir que el rescate/adopción prenatal es lícito porque no lesiona el acto conyugal o resguarda los bienes del matrimonio. El rescate y la adopción prenatal son acciones distintas a la FIV en sentido estrecho, y su objeto se debe juzgar de modo independiente. Sea para declararlo lícito o ilícito, su relación con la licitud de la FIV en sentido estrecho y los bienes del acto conyugal no acierta con el verdadero objeto de esta otra acción, y el argumento con ello equivoca el punto.

Tal como se dijo en la Primera Parte, podría pensarse en una transferencia de embrión y embarazo heterólogo de un embrión concebido naturalmente y dentro del matrimonio; y en un caso como este no cabría argumentar que esta práctica es lícita porque no lesiona el acto conyugal. Su ilicitud proviene de la violación de la dignidad de la persona del embrión, de quien se dispone (se viola su indisponibilidad) al transferirlo e implantarlo en una mujer que no es su madre genética.

\section{Subrogación y adopción}

Otro argumento que se repite en este debate es si el rescate/adopción prenatal es equivalente a la subrogación ("madre de alquiler") y condenable por las mismas razones. G. Grisez afirma que si no es inmoral que un niño sea alimentado por una nodriza, incluso pagándole, mucho menos sería que una mujer generosamente se embarazara de un embrión heterólogo para darle la oportunidad de vivir e, incluso, una familia ${ }^{55}$.

55 El argumento lo desarrolla en "Should a woman...". Miranda también lo aprueba y hace la analogía con los trasplantes o intervenciones que se justificarían por el principio de solidaridad (“¿Se pueden...”, 2). 
Para este autor, la diferencia entre esta práctica y la subrogación es que en la primera no existe contrato de por medio ni tampoco una relación entre la producción del embrión y la mujer que lo gestará.

Con todo, cabría preguntarse si la principal razón por la que la Iglesia condena la subrogación es que exista un contrato. Aunque esto sin duda agrava la falta, cuando la DP señala que la adopción prenatal de embriones donados por parte de parejas infértiles es condenable por las mismas razones que la subrogación (cf. DP 19), no se está refiriendo ni al contrato ni a la estrecha relación entre la FIV y la madre de alquiler. Ninguno de estos dos elementos está presente en la adopción prenatal. De hecho, lo único que sí tienen en común estas prácticas es la transferencia y gestación de un embrión heterólogo, por lo que una interpretación correcta de este pasaje debería identificar esos elementos comunes y concluir a partir de ellos la ilicitud de estos casos ${ }^{56}$.

En consecuencia, si bien el rescate/adopción prenatal son acciones muy diversas a la subrogación, su objeto es también malo y debe considerarse ilícita. ¿Y por qué no se condena a una nodriza? Probablemente por las mismas razones por las que no se puede equiparar una adopción prenatal con la adopción de un niño ya nacido -aunque quienes defienden la primera también utilizan este argumento-. En una adopción convencional existe un niño que está naturalmente vivo y que si se permite que la naturaleza siga su curso (si no se interviene en sentido contrario) seguirá desarrollándose y creciendo. El caso de los embriones criopreservados es exactamente opuesto: En relación con ellos, si no se interviene en sentido contrario el embrión terminará muriendo -o al menos “suspendido-". Además, en el caso de la nodriza la 'intervención' no viola la dignidad del niño (al contrario, no alimentarlo es una omisión culpable), mientras que la transferencia de un embrión criopreservado al útero de una mujer extraña sí es una manipulación o cosificación de la persona.

Además, si bien es cierto que el niño tiene derecho a ser engendrado, gestado, dado a luz y educado en el seno de una familia (cf. DV A 1,

56 Este pasaje se inserta en el acápite en el que se condena toda procreación heteróloga. Esto reafirma mi conclusión ya que el único elemento que comparten la procreación heteróloga, la subrogación y la adopción prenatal es la transferencia y gestación heteróloga. Todas sus otras características son distintas (contrato, relación directa con la FIV, intención, etc.). 
DV A 3), y que en el caso de las adopciones convencionales esta continuidad se rompe entre la gestación y la crianza; no es posible concluir sin más que escindir el proceso ahí o entre la concepción y la gestación es lo mismo. En primer lugar, las condiciones en que está la persona (naturalmente creciendo o "suspendida") son diversas. Y en segundo lugar, siguiendo la interpretación de Pastor, en la DP se ve incoada la explicitación de un nuevo criterio moral, producto de la profundización en la reflexión antropológica que estos adelantos biotecnológicos han impulsado: El deber de la no disyunción entre la maternidad genética y la gestacional ${ }^{57}$. Tonti-Filippini también se refiere a este punto al decir que durante la gestación el embrión está “en casa”; i.e. la gestación no se reduce a proporcionar nutrientes y soporte físico al que está por nacer, sino a una unidad biológica y espiritual, a una dependencia e interrelación dinámica entre madre e hijo que no es delegable ${ }^{58}$.

PDE

Otro argumento que se ha dado para defender el rescate/adopción prenatal es el de que la acción debería evaluarse moralmente con el Principio de Doble Efecto. Este principio se aplica cuando una acción produce dos efectos, uno bueno, que es el que se intenciona, y otro malo, que no se quiere pero se tolera porque está inevitablemente unido al primer efecto; es decir, es imposible obtener el efecto bueno sin que se produzca también el malo. Para que este principio pueda aplicarse deben cumplirse otras condiciones: que el objeto de la acción sea bueno o indiferente; que la intención sea buena; que el efecto malo sea posterior o al menos simultáneo al bueno (i.e. que el fin no justifique los medios) y que haya proporcionalidad entre ambos (que el efecto bueno sea tan importante que se justifique tolerar, sin desear, el malo) ${ }^{59}$.

$\mathrm{Al}$ respecto, señala W. E. May que en el rescate/adopción prenatal “la mujer [que] opta por transferir el embrión desde el tanque de nitrógeno a su matriz, por amor a él, no está escogiendo ninguna acción mala en sí. Como consecuencia de esta elección, permite ser embarazada y prevé

L. M. PAstor, “Análisis...”, 40.

58 N. Tonti-Filippini, “The embryo...", 119, también señala que la gestación aporta un cambio ontológico en el que se crea una nueva relación: la maternidad.

59 Cf. A. Gómez-Lobo, Los bienes..., 107. 
que quedará encinta. Pero esta no es la primera acción que realiza, ni lo que libremente escoge" 60 .

De acuerdo con el análisis de la Primera Parte este planteamiento tiene problemas. El objeto que identifica May sí es (al menos parcialmente) correcto. La diferencia es que, según mi interpretación, ese es precisamente el objeto intrínsecamente malo, pues comporta una violación a la indisponibilidad del embrión. La intención "por amor a él" es una intención buena. Pero los dos efectos que el autor señala -permite ser embarazada y quedar encinta- parecen de hecho ser un único fenómeno, pues ser embarazada y quedar encinta son dos modos de decir lo mismo, salvo que ser embarazada se entienda como la trayectoria e implantación del embrión en el útero, en cuya caso sería sinónimo de la transferencia, que es lo que identificó como objeto.

Los efectos de la acción de rescate/adopción prenatal son el embarazo heterólogo y salvar una vida. El efecto malo es el embarazo heterólogo pues comporta una violación a la dignidad del embrión, y el efecto bueno es salvar la vida del mismo. Estos dos efectos pueden entenderse como simultáneos. Pero aunque la intención sea buena y el efecto malo no sea la causa del bueno (condiciones 2 y 3 del Principio de Doble Efecto), entre los dos efectos no existe proporcionalidad (condición 4), puesto que el respeto a su dignidad de la persona es un bien irrenunciable que sobrepasa incluso la promoción de la vida. En consecuencia, al menos dos de las condiciones no se cumplen (licitud del objeto y proporcionalidad), por lo que el PDE no puede justificar esta acción.

M. Migliorino utiliza el mismo PDE para mostrar que la única alternativa moralmente lícita es descongelar y dejar morir a los embriones abandonados ${ }^{61}$. Dice que sacarlos del congelador tiene dos efectos: liberarlos de la injusticia en que están sometidos (efecto bueno y deseado) y la muerte de los embriones (efecto malo, no deseado pero previsto). El objeto de la acción (sacarlos del congelador) no es malo en sí mismo; la intención es buena (traerlos a la dimensión de la temporalidad y permitir que mueran naturalmente); el efecto bueno (liberarlos de la

60 W. E. MaY, "Catholic bioethics and the gift of human life" en Our Sunday Visitor Publishing, Huntington, 2000, citado por Bonet, "El debate...", 526.

61 M. Migliorino, "Adopting embryos: Here is why not". NCRegister.com May 24-30, 2009,3 (http://www.prolifesociety.com/prolifesociety/pagesArticlesAndPublications/ AdoptingEmbryos.pdf). 
injusticia) es previo al malo (su muerte), y hay proporcionalidad (se vela por la dignidad del embrión protegiéndolo de futuros manipulaciones). En este caso se probaría, a través del PDE, la licitud de descongelarlos para dejarlos morir naturalmente.

\section{Pendiente resbaladiza}

Muchos defensores del rescate/adopción prenatal advierten que si estas prácticas se aprueban existe el riesgo de la llamada pendiente resbaladiza, o el habitual fenómeno de que tras permitir la realización de determinada acción, el juicio (o la legislación) se vaya progresivamente relajando hasta aceptar la realización de otras acciones que se consideran imprudentes o incluso ilícitas. Algunos autores intentan prevenir este fenómeno poniendo condiciones a la práctica del rescate/adopción prenatal $^{62}$, pero condiciones que son bastante utópicas (como que se prohíba la criopreservación) o bien contradictorias con el principio de solidaridad que considera como un bien primario y principal salvar la vida del embrión.

Por ejemplo, en relación con las prácticas imprudentes o desaconsejables que podrían ir legitimándose, Bonet señala que si se aprueba la adopción prenatal sería difícil prohibir luego el rescate, que es desaconsejable en cuanto somete al niño que está por nacer a un quiebre entre lo biológico y lo social. No obstante, "no se trataría de una acción mala en sí, porque salva la vida, pero es desaconsejable" ${ }^{63}$. Luego podría también comenzar la adopción por parte de mujeres solteras, divorciadas o lesbianas, "que privaría al embrión de una familia bien constituida". Tanto en el rescate como en estos casos nos encontramos con el problema de que si salvar una vida es lo que justifica esta práctica, el derecho a la familia o el desaconsejar salvar una vida por no proporcionar una familia, parece

62 Un ejemplo es M. LÓPEZ-BArahona, "Adopción prenatal: Una alternativa legítima para los embriones congelados" (http://www.bioeticaweb.com/content/ view/109/49/). Dice que se debe comenzar por prohibir la generación de más embriones de los que serán transferidos en la FIV; que habría que conocer el número de embriones criopreservados en cada clínica; obtener el consentimiento informado de los padres genéticos; descongelar cronológicamente; prohibir el diagnóstico prenatal; la maternidad subrogada; considerar los criterios de idoneidad de los padres adoptivos, etc.

63 E. Bonet, "El debate...", 544. 
ser una contradicción en cuanto otro bien sobrepasaría a el que se supone justifica esta práctica ${ }^{64}$.

Otras consecuencias indeseables que se podrían seguir de declarar la licitud del rescate/adopción de embriones podrían ser, según estos autores, la comercialización de embriones, en la que afirman sería lícito participar por "la importancia del bien que se defiende" o "en beneficio de una vida que es tomada en serio" ${ }^{\circ}$. Sin embargo, si la Iglesia no admite siquiera el embarazo con embriones donados (cf. DP 19), mucho menos podría admitir el comercio de los mismos ${ }^{66}$. La vida no puede estar por sobre la dignidad.

\section{Una acción ilícita}

Finalmente hay otras dos razones que muestran por qué el rescate/adopción prenatal se opone a las enseñanzas del Magisterio. Una es la cooperación material al mal. Los autores que defienden estas prácticas afirman que ellas no constituyen cooperación al mal -que está explícitamente prohibida- (DP 35). Arguyen que los rescatistas/adoptantes no tienen responsabilidad por la $\mathrm{FIV}^{67}$; que pagar a las instituciones que criopreservan podría restringirse a pagar al personal que realiza la transferencia para que el pago no fuera importante ${ }^{68}$; que si bien podría implicar selección de embriones esta se realizaría con un criterio terapéutico ${ }^{69}$, etc.

64 La contradicción es más clara respecto del rescate/adopción por parte de mujeres consagradas, al que Bonet se opone diciendo es distinto al caso de mujeres solas o lesbianas porque su condición de consagradas vuelve imposible un proyecto familiar ("El debate...", 536). Es decir, la vida cede ante la familia. Cf. E. Bonet, "El debate...", 541.

66 Si la mediación de un contrato es un agravante para la subrogación, es precisamente porque convierte a las personas (los embriones) en bienes transables, i.e. exactamente lo opuesto a un bien indisponible.

67 C. Brugger, "Rescuing...”, 4.

68 Cf. E. Bonet, "El debate...”, 541.

69 Cf. E. Bonet, “El debate...”, 543. El autor señala que la situación sería análoga a un trasplante en el que solo hay un órgano y varias personas que lo requieren. En este caso los médicos deben elegir a quién operarán, tomando en consideración distintas variables como, por ejemplo, la posibilidad de éxito. Con los embriones criopreservados se tendrían que descongelar y transferir aquellos que se estimen viables. Esto contrasta con la opinión de López Barahona, quien pone como condición que los embriones se vayan descongelando cronológicamente para evitar, precisamente, una selección que podría llegar a ser eugenésica. 
No obstante, aunque todas estas razones fueran verdaderas y no existiese cooperación material al mal, la DP afirma que "el criterio de independencia no es suficiente" (DP 35) ${ }^{70}$. Y agrega: "Cuando el delito está respaldado por las leyes que regulan el sistema sanitario y científico, es necesario distanciarse de los aspectos inicuos de esos sistemas, a fin de no dar la impresión de una cierta tolerancia o aceptación tácita de acciones gravemente injustas. De lo contrario se contribuiría a aumentar la indiferencia, o incluso la complacencia con que estas acciones se ven en algunos sectores médicos y políticos" (DP 35). Después, para subrayar que estos principios no son se reducen a la práctica que allí se discute, afirma que este deber "deriva de la obligación de separarse, en el ejercicio de la propia actividad de investigación, de un marco legislativo gravemente injusto y de afirmar con claridad el valor de la vida humana. Esto vale también en ausencia de cualquier conexión próxima de los investigadores con las acciones de los técnicos e la procreación artificial..." $(\text { DP } 35)^{71}$.

El otro argumento que se repite para legitimar esta práctica es el del mal menor. Se reconoce, por ejemplo, que existe cierta instrumentalización de la mujer, pero se afirma que es tan grande el bien que se persigue que esta, aun siendo mala, se tolera. También se dice que "el mal ya está hecho y solo queda optar por lo menos malo" y que "se puede realizar el mal en razón de una necesidad imperante" 72 . Al respecto hay que tener muy claros los criterios de evaluación moral. De acuerdo con el PDE, hay circunstancias en que es lícito y necesario tolerar algún mal (aquel que está inevitablemente unido al bien que se persigue). Pero tolerar no significa, en ninguna circunstancia, realizar o intencionar el mal. La Iglesia afirma que jamás se puede intencionar un mal, ya que en ese caso la acción no es ordenable a Dios, lo que implica que viola la ley natural

70 La DP discute el tema en la sección dedicada al uso de material biológico humano de origen ilícito, pero aclara expresamente que "conviene enunciar los principios generales a partir de los cuales quienes actúan en recta conciencia puedan evaluar y resolver..." (DP 34. Cursivas mías).

71 Aunque estas indicaciones se dirigieran solo a profesionales del ámbito biomédico, basta pensar que si ellos estén moralmente impedidos para realizar el procedimiento este no se puede llevar a cabo.

72 Cf. E. Furton en "On the disposition...” y declaraciones de R. George en B. Caulfield, "Pregnant Pause: Where do frozen embryos belong?", Human Life Review, verano 2001. http://www.humanlifereview.com/index.php/archives/152001-summer/26-pregnant-pause-where-do-frozen-embryos-belong). 
constituyendo una violación a la dignidad de la persona, el único bien irrenunciable.

Ahora bien, quienes intentar justificar el rescate/adopción prenatal con la doctrina del mal menor están, implícitamente, reconociendo que el rescate/adopción prenatal es un mal, menor que otros, pero un mal. En segundo término, el rescate/adopción prenatal es una acción que la persona intenciona y realiza. No es un efecto que se tolere, sino un mal que se está intencionando directamente, por lo que no existe modo de eludir la responsabilidad moral de realizarlo. La doctrina del mal menor contraría las enseñanzas del Magisterio.

\section{CONCLUSIÓN}

Cuando la DV afirma que los embriones sobrantes viven una situación absurda y que no existen vías lícitas de supervivencia (cf. DV I 5), no se equivoca. Tal como sucede con la fecundación artificial, en que debido a la manipulación que se hace de la persona y su disconformidad con los actos específicamente humanos "la procreación queda privada de su perfección propia” (DV B 4), la gestación heteróloga también implica la manipulación de una persona, la violación de su dignidad y, con ello, queda privada de su perfección propia.

Todo niño tiene el derecho a tener un origen plenamente humano, adecuado a la naturaleza personal del ser humano. Tanto el aborto, en un extremo, como el encarnizamiento reproductivo, en el otro, se oponen a este derecho. La "dinámica de violencia y dominio" a la que conduce la mentalidad abortista de nuestra época y que hace que "el hombre se [haga] dominador de la vida y de la muerte" (DV I 5) es la que, en ambos casos, está operando ${ }^{73}$. Esta mentalidad tan difundida puede también, en un primer momento, contaminar la mirada de quienes son contrarios a estas prácticas, y no dejarles advertir que bajo la loable intención de salvar una vida se está violando la dignidad de una persona.

¿Pero qué se hace entonces con los miles de embriones criopreservados? Los embriones criopreservados son embriones sobrantes, a quienes se les mantiene artificialmente con vida por medio de un procedimiento

73 Y que es también la misma que informa tanto la eutanasia como el encarnizamiento terapéutico. Como dice EV 22, "[r] ecurriendo a cualquier forma de tecnología, [el hombre] se afana por programar, controlar y dominar el nacimiento y la muerte”. 
indigno (congelados), a la espera de que eventualmente los "usen". Es decir, son personas a las que no se las deja morir $^{74}$.

En efecto, si no se impidiera el curso natural de los acontecimientos, estos embriones no implantados morirían. Pero se dispone de ellos y se detiene su vida a la espera de que un tercero, por una decisión arbitraria, vuelva a disponer de ellos para implantarlos en el momento que ese tercero decida. A estos embriones sobrantes se les impide su proceso de muerte natural a la espera de que se vuelva a violar su indisponibilidad, su dignidad; y se les vuelva a tratar como objetos, como inferiores a merced de quienes sean sus dueños.

En consecuencia, y a pesar de lo doloroso que resulta comprobar que efectivamente a través de la FIV se realiza una "injusticia irreparable", la única posibilidad digna para estos embriones, estas personas, es dejarlas morir. La Iglesia defiende la vida desde la concepción hasta la muerte natural (cf. DV III), y la defiende por la dignidad de cada persona humana. Mantener a una persona artificialmente viva -como los embriones congelados- es moralmente condenable. Y disponer de ella, transfiriéndola en el momento en que un tercero decida desde el congelador a un útero desconocido, es una nueva violación a la dignidad de esa persona. La medida para la evaluación moral no es otra que la verdad ontológica de la persona (cf. DP 5), la que se descubre en un análisis antropológico que logre ver la especificidad de las acciones humanas. Todo juicio moral debe remitirse a "esas normas no escritas" (DP 6) que están inscritas en nuestra naturaleza y que constituyen la piedra de toque del respeto a nuestra dignidad. Y tanto el llamado rescate como la adopción prenatal contradicen la especificidad de la procreación humana, lo que lo convierte en una acción inmoral.

74 El "encarnizamiento reproductivo" que se daría en la criopreservación puede considerarse incluso más violento que el encarnizamiento terapéutico. En este último las intervenciones médicas se empeñan (aunque excesivamente) en ayudar a que el enfermo siga realizando las operaciones que le son propias. Dentro del tanque de nitrógeno, en cambio, la tecnología impide que los embriones realicen las operaciones que les corresponde en cuanto seres humanos vivos, se les fuerza a inhibir su actividad natural y se silencia la manifestación de su naturaleza. Agradezco este comentario al profesor Antonio Amado. 
